\title{
Preparation and characterization of olive pit powder as a filler to PLA-matrix bio-composites
}

\author{
A.F. Koutsomitopoulou ${ }^{a}$, J.C. Bénézet ${ }^{\text {b,* }}$, A. Bergeret ${ }^{\text {b }}$, G.C. Papanicolaou ${ }^{\text {a }}$ \\ a Composite Materials Group, Department of Mechanical and Aeronautics Engineering, University of Patras, Greece \\ ${ }^{\mathrm{b}}$ Centre des Matériaux de l'Ecole des Mines d'Ales (C2MA), Ecole des Mines d'Alès, France
}

\begin{abstract}
A B S T R A C T
This study is focused on recycling potential of some waste materials, such as olive pits, i.e. the solid phase derived from an olive oil mill, blended with thermoplastic polymers and used for the production of new materials applied in manufacturing containers and formworks. The olive pit powders are described and characterized. Then the powder is introduced in a bio-based and biodegradable matrix (polylactic acid, PLA) at various percentages. In this study, a comparison of the size distribution and the densities of olive pit powders according to the grinding methods (planetary mill and centrifugal mill) was made. The analyses showed that olive pits can be further studied as additive for the production of green materials. The development of an agricultural based polymer matrix compatible with olive pits and consequently a fully biodegradable composite system is the future and ultimate goal of the research undertaken. For that purpose, composite samples made out of PLA matrix, reinforced with olive pit powders were manufactured and mechanically characterized. With filler loading, an increase in the tensile modulus but a decrease of the flexural strength may be due to the poor interfacial bonding between olive pit powder and PLA.
\end{abstract}

Keywords:

Olive pit powder

PLA

Grinding

Size distribution

Morphology

Mechanical properties

\section{Introduction}

Nowadays there is a significant interest for the development of environmentally friendly polymers and polymer composites based on renewable resources due to the increasing environmental concerns and the decreasing fossil resources [1]. Bioplastics in comparison with the traditional plastics offer several and functional benefits, but they are not yet industrialized in a large scale. Cost, which in some bioplastics is at least twice compared to traditional petroleum-based polymers, is a drawback and a reason that leads to low manufacture capacity of these polymers [2].

Biodegradable polymers such as polylactic acid (PLA), cellulose esters, polyhydroxyalkanoates (PHA) and starch polymers can be reinforced with natural-based fillers to produce eco-friendly composites [3]. Among the biodegradable polymers, PLA is commercially available produced in large-scale [3] and able to compete with other traditional petroleum-based polymers such as PET. PLA is a thermoplastic polymer belonging to the aliphatic polyesters derived by alpha hydroxy acids (AHAs) which can be produced by carbohydrate fermentation or chemical synthesis [4].

Olive pits are residues, part of the soil wastes of the olive oil manufacturing industry produced by the processing and extraction of

\footnotetext{
* Corresponding author at: Ecole des Mines d'Alès C2MA, 6 Avenue de Clavières, 30319 Alès Cedex, France. Tel.: + 33466785362

E-mail address: Jean-Charles.Benezet@mines-ales.fr (J.C. Bénézet).
}

olive oil from olives. It is commonly use so far as biofuel in the form of pellets due to high combustion power $[5,6]$.

In this study a novel biodegradable composite material containing olive pit powder dispersed into PLA was manufactured and studied. The aim of this study was to investigate the effect of three types of olive pit powders at different weight fractions on the physical and mechanical properties of PLA composites.

\section{Materials and methods}

Polylactic acid (PLA) 7000D® in pellets form was supplied by Nature Works, USA. It has a molecular weight, $M_{n}=199.600 \mathrm{Da}$, specific gravity of $1.24 \mathrm{~g} / \mathrm{cm}^{-3}$ and polydispersity index $=1.78$ (SEC, THF, $25^{\circ} \mathrm{C}$ ). PLA has a glass transition temperature, $\mathrm{T}_{\mathrm{g}}=61^{\circ} \mathrm{C}$, and a melting temperature, $\mathrm{T}_{\mathrm{m}}=153{ }^{\circ} \mathrm{C}[8]$.

Olive pits used in this study were supplied by local olive manufacturers from the region of Messinia located in southern west of Peloponnesus (Greece) after the end of the olive oil extraction process. The oil olive extraction includes several stages. After the harvesting, olives were scoured with clean water and then were air drained. Then, they were placed in proper metallic crashers and grounded up into a homogeneous pulp. For further olive oil extraction the pulp was placed in a downstream-arranged blender for about 20 to $45 \mathrm{~min}$. During olive oil extraction process, it is possible for olive stones to be partially crushed in smaller pieces. The next step is to separate the oil from the water and waste solids with centrifugation. Olive pits used in this work were part of the waste solids that were obtained from the end of the olive 
oil extraction process. They were cleaned and washed out with water in order to be separated from their impurities, produced during the olive processing, without having further any physical or chemical modification treatment. Then, they were placed in an oven at $110{ }^{\circ} \mathrm{C}$ for $24 \mathrm{~h}$ in for the removal of their enclosed moisture [9].

\subsection{Raw material preparation}

For the powder preparation, two different grinding procedures were applied, producing three types of olive pit powder. Various measurements were accomplished to determine characteristics such as the density and the size distribution and the shape of the powder. Different olive pit/PLA composites were manufactured at different weigh fractions and different particle size distributions. Three different groups of composites were manufactured. These groups of composites consisted of one group with mean particle filler diameter, $d=30 \mathrm{~mm}$, at wt.\% $=5$, and 10 (PLA/olive pit powder $\mathrm{A}$ ) and another two groups with particle diameter $\mathrm{d}=60$, and $170 \mathrm{~mm}$ at wt.\% $=5,10,15$, and $20 \mu \mathrm{m}$ (PLA/olive pit powders B and C, respectively).

Three different olive pit powders (called A, B and C from the finest to the coarsest) are produced using different milling conditions. For milled olive pit A, a sample of olive pits was firstly grinded with a coffee electric grinder for $10 \mathrm{~min}$ in order to reduce the volume of the soft material. This was followed by a second milling in agate bowl with agate balls (2 mm diameter), at $600 \mathrm{rpm}$ torque motor speed for $30 \mathrm{~min}$ with cycles $10 \mathrm{~min}$ milling and $1 \mathrm{~min}$ pausing in a Planetary Mono Mill pulverisette 6 (Fritsch).

On the other hand, olive pit powders $B$ and $C$ are produced using another grinding method a high speed rotor Ultra Centrifugal Mills ZM 200 , Retsch. In this case, the influence of the speed rotor (ranged between 6000 and $12,000 \mathrm{rpm}$ ) and of the ring sieve diameter ( 0.2 or $0.5 \mathrm{~mm}$ ) for a milling duration of $15 \mathrm{~min}$ on the size particle is studied. Fig. 1 shows the particle volume distributions as a function of the particle mean diameter for different torque speeds. The duration of the milling process as well as the ring sieve diameter were retained constant in all the different grindings. What was finally chosen among all different torque speeds applied for the olive pit powder types B and C was a rotor speed of 6.000 . Olive pit powder $C$ corresponds to that sieved using a Vibratory Sieve Shaker (Retsch). Olive pit powders were dried in an oven for $24 \mathrm{~h}$ at $110{ }^{\circ} \mathrm{C}$. Then, the powders were stored inside a humidity chamber with controlled environmental conditions (low humidity).

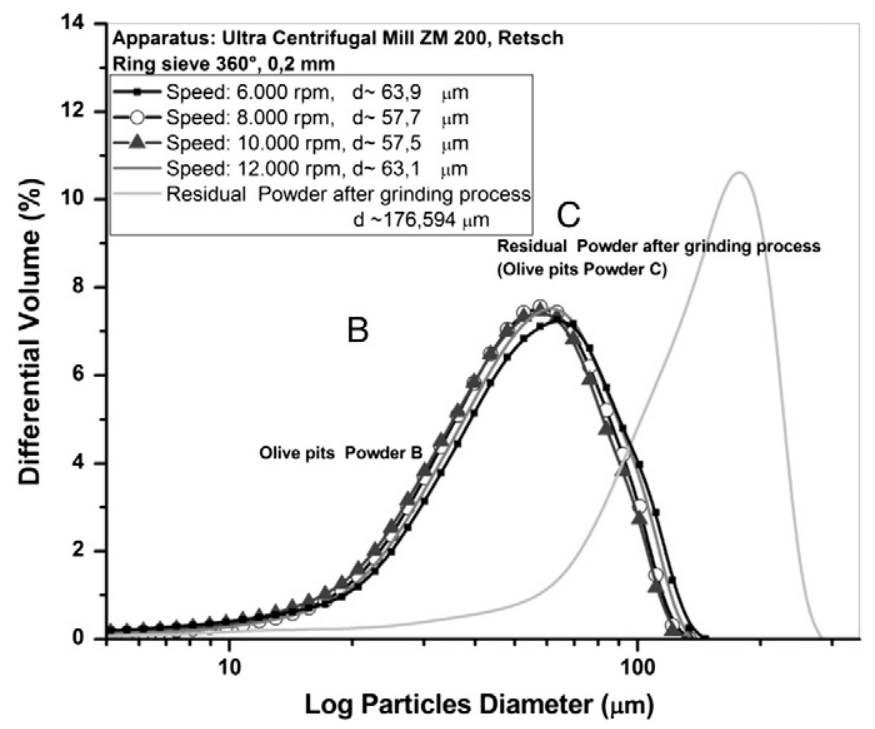

Fig. 1. Particle volume distributions as a function of the particle mean diameter for different torque speeds.

\subsection{Measurements of the size distribution of the olive pits}

The size distribution of the olive pit powder was determined with a LS'M 200, Beckman Coulter laser diffraction particle size analyzer. The measurements of the samples were in aqueous (purified environment) environment. The samples were pre-dispersed in water in order to accomplish better dispersion of the particles. Table 1 summarized the olive pit powder size obtained by the different grinding methods applied.

\subsection{Measurements of density}

Absolute density is determined when the volume measured excludes the pores as well as the void spaces between particles within the bulk sample. There are many techniques for measuring this type of density. In the present study, absolute density is determined by measuring the helium pressure change in a calibrated volume (He Pycnometer, AccuPyc 1330 Micromeritics).

The bulk density for porous materials is defined as the density measured by considering the overall volume of the material; including pore volume. The tap or pack density is obtained from filling a container with sample material and vibrating it to obtain near optimum packing. Such a measurement is of great interest in packing and shipping items like bulky products. Tap density is not an inherent property of a material but depends on particle size distribution and shape as well as measurement techniques.

The density of the olive pit powders A, B and C was determined with a PT-N Hosokawa Powder Tester.

\subsection{Thermogravimetric analysis (TGA)}

Thermogravimetric analysis was performed using a STA 409 Cell, Netzsch, thermogravimetric analyzer. The olive pit powders were heated from ambient temperature to $800{ }^{\circ} \mathrm{C}$ at a heating rate of $10^{\circ} \mathrm{C} / \mathrm{min}$ in the presence of argon.

\subsection{Thermic analysis (DSC)}

The melting and crystallization behaviors of PLA/olive pit composites were studied by means of Differential Scanning Calorimetry (DSC), PerkinElmer-Pyris 1 (USA), under flow conditions of dry gaseous $\mathrm{N}_{2}$ as the purge gas. DSC measurements were performed within the temperature range of $30-200{ }^{\circ} \mathrm{C}$ using $8.0 \pm 0.1 \mathrm{mg}$ of PLA and/or PLA/olive pit composites sealed in special aluminum sample pans. The samples were heated from $30{ }^{\circ} \mathrm{C}$ to $200{ }^{\circ} \mathrm{C}$, kept at this temperature for 3 min to completely eliminate any possible crystalline phase developed and then cooled back to $30^{\circ} \mathrm{C}$.

This heating/cooling procedure was repeated for a second time under the same conditions. The heating/cooling rate applied was in both cases $10{ }^{\circ} \mathrm{C} / \mathrm{min}$ under $\mathrm{N}_{2}$ flow conditions at a rate of $20 \mathrm{~mL} / \mathrm{min}$. Details on the thermal profile just described are shown in Table 1. From the thermographs obtained, thermal properties such as the glass transition temperature $\left(T_{g}\right)$, cold crystallization temperature $\left(T_{c c}\right)$ and melting temperature $\left(\mathrm{T}_{\mathrm{m}}\right)$ were determined.

The percentage degree of crystallinity of the neat PLA as well as the PLA/olive pit composites of each sample was calculated from the

Table 1

DSC thermal profile.

\begin{tabular}{ll}
\hline DSC thermal profile & \\
\hline 1st run & 2nd run \\
1. Hold for 3 min at $30{ }^{\circ} \mathrm{C}$ & 1. Cool from $200{ }^{\circ} \mathrm{C}$ to $30{ }^{\circ} \mathrm{C}$ at $10{ }^{\circ} \mathrm{C} / \mathrm{min}$ \\
2. Heat from $30{ }^{\circ} \mathrm{C}$ to $200{ }^{\circ} \mathrm{C}$ at $10{ }^{\circ} \mathrm{C} /$ min & 2. Hold for 3 min at $30{ }^{\circ} \mathrm{C}$ \\
3. Hold for 3 min at $200{ }^{\circ} \mathrm{C}$ & 3. Heat from $30{ }^{\circ} \mathrm{C}$ to $200{ }^{\circ} \mathrm{C}$ at $10{ }^{\circ} \mathrm{C} / \mathrm{min}$ \\
\hline
\end{tabular}


thermographs that were obtained from the first and second heating runs as follows:

$\left(0 /{ }_{0}\right) X_{C}=\frac{\Delta H_{m}-\Delta H_{C C}}{\Delta H_{m}^{\infty}}$

[10] where, $\Delta H_{m}$ is the measured endothermic enthalpy of melting, $\Delta H_{C C}$ is the exothermic cold crystallization enthalpy and $\Delta H_{m}^{\infty}$ is the enthalpy of melting for a $100 \%$ crystalline PLA. The theoretical $\Delta H_{m}^{\infty}$ was considered to be $93.0 \mathrm{~J} / \mathrm{g}[11,12]$.

\subsection{Scanning Electron Microscopy (SEM)}

The morphological characteristics of the olive pit powder as well as the area cross section of the polymeric matrix composites reinforced with olive pits were observed by means of an Environmental Scanning Electron Microscope (ESEM, FEI 200) working under normal environmental conditions.

\subsection{Biocomposite processing}

Before processing, all materials (PLA, powders) are dried under vacuum at $60{ }^{\circ} \mathrm{C}$ for $24 \mathrm{~h}$. Compounding is achieved by a co-rotating twin screw extruder (Clextral BC21, length 900 length, diameter $25 \mathrm{~mm}, 1.5 \times 40 \mathrm{~mm}^{2}$ flat die) with 12 heating zones (temperature profile: $30^{\circ} \mathrm{C}$ (feeder)/ $60{ }^{\circ} \mathrm{C} / 120^{\circ} \mathrm{C} / 150{ }^{\circ} \mathrm{C} / 175{ }^{\circ} \mathrm{C} / 175{ }^{\circ} \mathrm{C} / 175{ }^{\circ} \mathrm{C} / 175^{\circ} \mathrm{C} / 175{ }^{\circ} \mathrm{C} / 175{ }^{\circ} \mathrm{C} / 175$ ${ }^{\circ} \mathrm{C} / 1197{ }^{\circ} \mathrm{C}$ (die)). Screw speed rate is $250 \mathrm{rpm}$ and feed rate is $4 \mathrm{~kg} / \mathrm{h}$. After extrusion, injection molding is then carried out on a Krauss Maffei KM50-T180CX. Screw temperature is set at $200{ }^{\circ} \mathrm{C}$ and the mold temperature is maintained at $40{ }^{\circ} \mathrm{C}$. The injection cycle time is fixed at $60 \mathrm{~s}$. Olive pit powder contents vary in the $0-20 \mathrm{wt} . \%$ range in PLA.

\subsection{Mechanical testing}

A universal mechanical testing machine, Zwick (TH 010 model) was used to measure the tensile and bending properties according to the ISO 527 standard at room temperature. In all cases, a load cell of $10 \mathrm{kN}$ and constant crosshead speed of $1 \mathrm{~mm} / \mathrm{min}$ and $10 \mathrm{~mm} / \mathrm{min}$ for the tensile modulus and the tensile ultimate stress were applied respectively. All results presented are the average values of at least five tested measurements.

\section{Results and discussion}

\subsection{Chemical composition of olive pit powders}

Olive kernel is a lignocellulosic biomass which is composed by cellulose (37.5 wt.\%), hemicelluloses (26 wt.\%) and lignin (21.5 wt.\%). Other components include moisture (8 wt.\%), minerals (1 wt.\%) and proteins, pectines, tannins, etc. [6,7]. Their ultimate analysis was carried out using a CHN-LECO 800 Analyzer. Results showed mainly carbon and oxygen (49 and 31 wt.\% respectively) in agreement with Gonzalez et al.'s experiments [13]. Metal analysis conducted to the char showed mainly the presence of iron $(1236 \mathrm{mg} / \mathrm{kg}$ of olive pit) and aluminum ( $463 \mathrm{mg} / \mathrm{kg}$ ). Other metals found were $\mathrm{Zn}, \mathrm{Cu}, \mathrm{Ni}, \mathrm{Cr}$ and $\mathrm{Mn}$ with all amounts being in the range of $12-29 \mathrm{mg} / \mathrm{kg}$ of olive kernel.

\subsection{Size distribution of the olive pit powders}

Different torque rotor speeds were applied at samples of olive pit powders using the high speed rotor centrifugal mill. The 15 minute duration of the milling process and the ring sieve of $0.2 \mathrm{~mm}$ were kept constant in all the different grinding processes. A rotor speed of $6.000 \mathrm{rpm}$ was applied resulting to olive pit powder fractions B and C with mean sizes of approximately $60 \mu \mathrm{m}$ and $170 \mu \mathrm{m}$, respectively
(Fig. 1). These powder fractions were subsequently retained for further investigation.

The mean size distribution of powder A which was grinded by the planetary ball mill is shown in Fig. 2. The olive pit powder fraction A had mean diameter $\sim 30 \mu \mathrm{m}$. In this case what was observed was wide size dispersion in the granulometric factor comparing to the size distributions achieved with the centrifugal mill.

The observed size distributions can be attributed to the milling process; the water-olive pit particle interactions and to the time of immersion of olive pit particles into the water solution. Finally for our measurements the assumption of spherical particle shape was adopted. However, such an assumption is not a realistic one, since a complex shape of particles usually exists (Table 2).

\subsection{Density measurements of olive pit powders}

The bulk and pack density of the powder grades A and B and the absolute density of olive pit powder grade $C$, are given in Table 3.

The finest powder (A) in which no clusters exist, is characterized by the higher tapped density.

\subsection{Thermogravimetric analysis (TGA) of the olive pit powders}

The thermal stability of the natural materials incorporated into natural polymer matrices is of great importance for composite manufacturing since it affects their processability and their physical and mechanical behaviors. Samples of olive pit powders A and B were scanned in a TGA device from ambient temperature to $800{ }^{\circ} \mathrm{C}$ at a heating rate of $1{ }^{\circ} \mathrm{C} / \mathrm{min}$ in argon atmosphere. Respectively results are presented in Fig. 3.

As it can be observed from the respective diagrams, the different mechanical processing techniques applied for the olive pit powder preparation does not seem to affect their thermal behavior. More precisely, the two powders have shown almost the same thermal degradation temperature.

A weight loss of about $5 \%$ in $100-140{ }^{\circ} \mathrm{C}$ temperature range is due to the evaporation of the moisture entrapped into the molecular structure of the olive pit particles and to other residuals. Between 140 and $220^{\circ} \mathrm{C}$ the rate of weight loss is stable which indicates the temperature processability range of this material [14]. As the temperature increases the first step of degradation ( $-29 \%$ ) at $220{ }^{\circ} \mathrm{C}$ appeared. This degradation is attributed to the degradation of lignin and the hemicellulose. Above this temperature the extraction of moisture and the volatiles results to the formation of voids at the olive pit surface [14].

As the temperature is elevated, above $300{ }^{\circ} \mathrm{C}$, hemicellulose is essentially converted into gasses and acetic acid [15]. When the hemicellulose

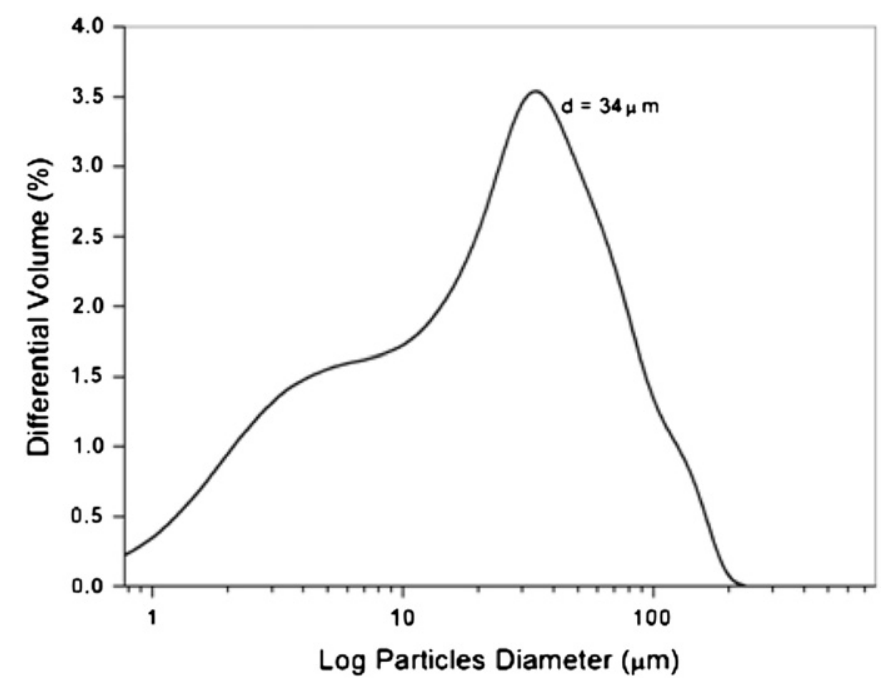

Fig. 2. Size distribution of olive powder A. 
Table 2

Grinding method and olive pit powder size.

\begin{tabular}{llc}
\hline Grinding method & Olive pit powder & Mean diameter $(\mu \mathrm{m})$ \\
\hline Ultra Centrifugal Mills ZM 200 & B & 60 \\
& C & 170 \\
Planetary Mono Mill pulverisette 6 & A & 30 \\
\hline
\end{tabular}

is already decomposed; the contribution on the increase in weight loss rate is attributed to the cellulose decomposition. The weight loss between 300 and $357{ }^{\circ} \mathrm{C}$ in which cellulose is decomposed is about $23 \%$. Above this temperature lignin continues to break down with a lower weight loss rate compared to that of the hemicellulose and cellulose $[7,16]$. The residual ash that was obtained from the procedure was about $20 \%$ of the total weight, but as it can be observed from the thermograph (Fig. 3) it was not fully stabilized and the samples could have been heated to temperatures higher than $800{ }^{\circ} \mathrm{C}$.

\subsection{Scanning Electron Microscopy (SEM) of the olive pit powders}

Through the scanning electron micrographs of the olive pit powders A, B and C, it can be seen the difference of the size distribution between the three powders (Figs. 4-7). This indicates that the milling process and the conditions play a major role affecting the dimensional and topological characteristics of the olive pit powders.

What can also be mentioned is that the grinding methods also affect the shape of the olive pit granules. As it is observed in Figs. 5-7, powders $A$ and $C$ have more or less a spherical shape in contrast with powder $B$ in which granules have a flake-like shape. The surface characteristics of the different olive pit granules depend on the type as well as the intensity and the time duration of the grinding method.

As it is well known [17], the difference in the physical and mechanical properties of the different PLA/olive pit composites might be attributed to the difference in olive pit granule shape, size as well as the size distribution of the different powders applied.

\subsection{Thermal properties of biocomposites}

DSC experiments were executed to study thermal capacity behavior of the PLA/olive pit powder biocomposites (Table 4). An increase in the crystalinity ratio with the presence of milled olive pits is observed that may suggest that the powders act as nucleating agents. The increase in the degree of crystallinity occurs for the 5 wt.\% specimens and for the larger particles (olive pit powder C) and for the $10 \mathrm{wt} . \%$ specimens for the finest particles (olive pit powders A and B). This result is in good agreement with those of Perinovic et al. [18] that found that olive pit powders act at the same time as nucleating agents at lower concentrations and as obstacles for PLA chains, to develop crystals, at higher concentrations. A slight decrease in all transition temperatures ( Tg, Tm and Tc) is obtained in presence of olive pit powders that is less pronounced for the finest powder (olive pit powder A).

Thermal stability of the PLA/milled olive pit biocomposites is also investigated through TGA experiments (Table 5). Results show that PLA thermal stability is decreased as the olive pit powder content increases for any powder granulometry which is in accordance with similar observations made by other authors on PLA/wood fiber biocomposites [19].

Table 3

Absolute, bulk and pack density of olive pit powders.

\begin{tabular}{lcc}
\hline \multicolumn{3}{l}{ Absolute density $\left(\mathrm{g} / \mathrm{cm}^{3}\right)$ of olive pit powder (grade C) $1.424 \pm 0.009$} \\
\hline & Olive pit powder A & Olive pit powder B \\
\hline Bulk density $\left(\mathrm{g} / \mathrm{cm}^{3}\right)$ & $0.383 \pm 0.003$ & $0.393 \pm 0.002$ \\
Pack density $\left(\mathrm{g} / \mathrm{cm}^{3}\right)$ & $0.725 \pm 0.010$ & $0.651 \pm 0.003$ \\
\hline
\end{tabular}

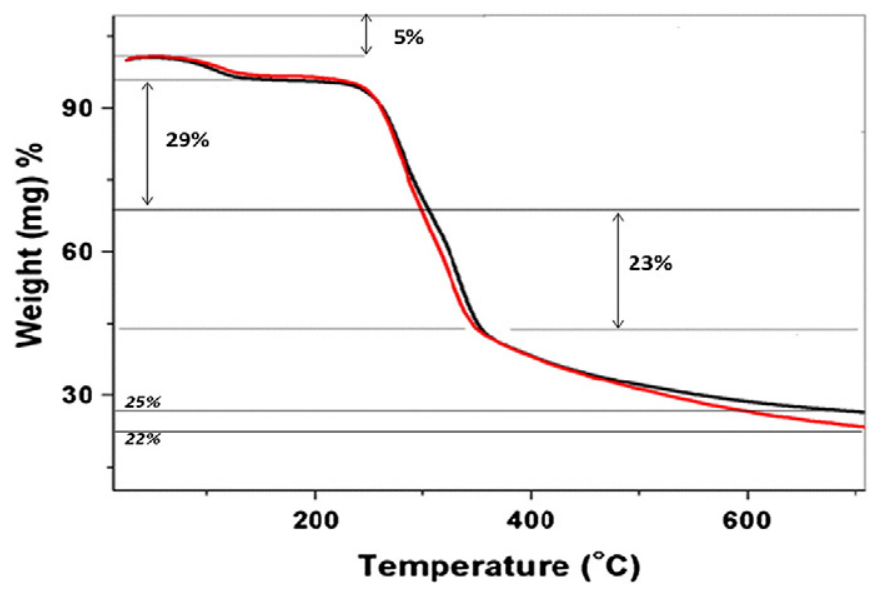

Fig. 3. Thermographs of olive pit powders A and B.

\subsection{Mechanical characterization of biocomposites}

Fig. 8(a) shows the variation of the tensile modulus as a function of the olive pit powder content of composites. Concerning the PLA/olive pit powder $\mathrm{B}$ and $\mathrm{C}$ composites, the tensile modulus gradually increases with increasing the filler content. At $20 \mathrm{wt}$.\% of filler content, the elasticity modulus of PLA/olive pit powder B and C composites increase at about $18 \%$ and $16 \%$ respectively compared to the neat PLA. In the case of the PLA/olive pit powder C at 5 and 10 wt.\% of olive pit powder content a normalized increase of $13 \%$ and $10 \%$ is respectively observed. In general, experimental deviations were $<10 \%$, showing an excellent repeatability. In this study, concerning mechanical characterization of PLA and PLA/olive pit powder composites, experimental results represent the mean value of at least five specimens tested.

Fig. 8(b) shows the PLA/olive pit powder A, B and C composite tensile strength variation as a function of filler content. At higher weight fractions of olive pit powder, tensile strength slightly decreases due to the filler high volume incorporated into the PLA matrix. What is also observed is that the mechanical properties are more effectively enhanced in the case of biocomposites in which, PLA is incorporated with olive pit powders $\mathrm{B}$ and $\mathrm{C}$. In the case of olive pit powder type $\mathrm{A}$, the agglomeration and the poor dispersion of the fillers into the PLA matrix, initially had a significant impact on the mechanical properties of the composite in comparison to the neat matrix strength. This behavior might be attributed to the grinding method applied which affects the olive granule size and size distribution as well as their physical and morphological characteristics.

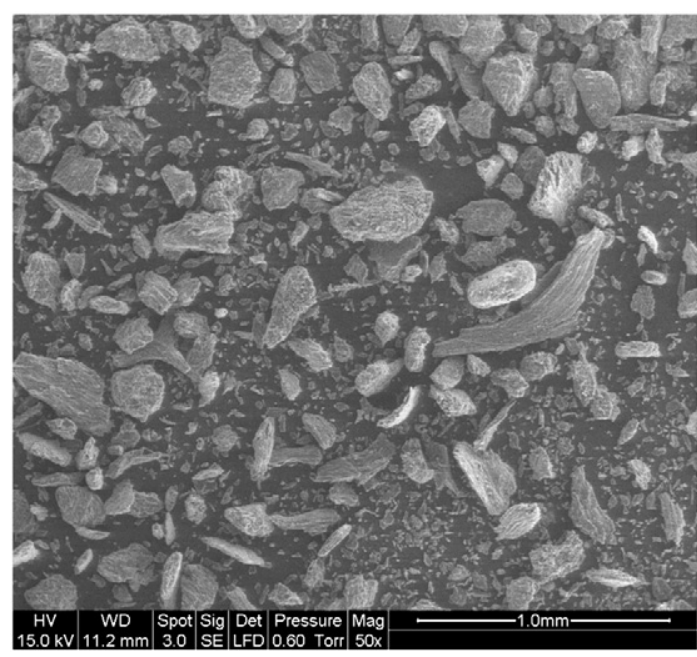

Fig. 4. Ungrinded olive pits, mag. $50 \times$. 


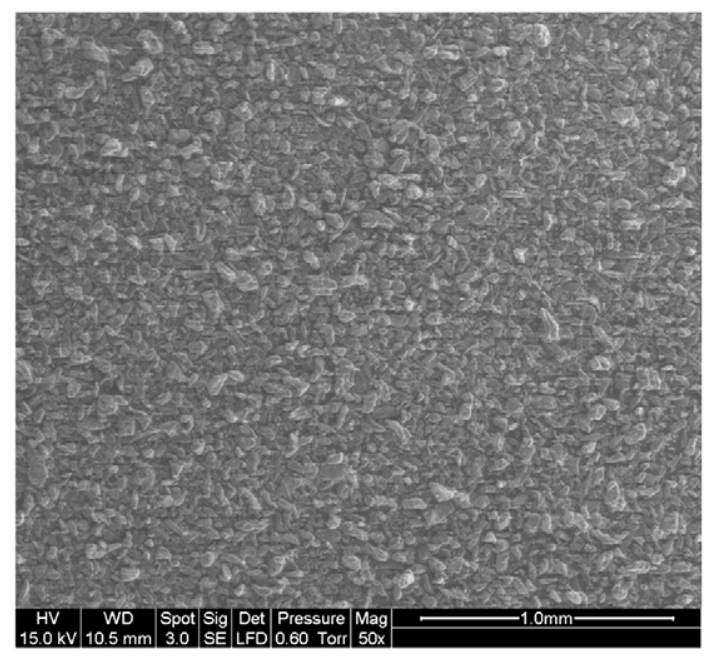

Fig. 5. Olive pit powder A, mag. $50 \times$.

This behavior might be attributed to the effect of the type as well as the intensity of the grinding method applied. Powders A and B show a fine distribution with particles of almost spherical shape while powder $C$ showed a coarse distribution with particles of irregular shape.

Fig. 8(c and d) shows the flexural modulus and strength variation of the PLA/milled olive pit biocomposites as a function of the weight fraction of the milled olive pits and of their size. Flexural modulus increases as the powder weight fractions increase, especially for milled olive pits $B$ and $C$. Nevertheless, when smaller particles are used (olive pit powder A), a reduction in both tensile and flexural modulus is obtained for weight fractions equal to $10 \%$ which might be connected with agglomeration phenomena existed. Tserki et al. [20] observed also an increase in Young's modulus upon olive husk flour (125 $\mu \mathrm{m})$ addition in a polybutylene succinate (PBS) biodegradable biopolyester from about $375 \mathrm{MPa}$ for the unfilled PBS to $750 \mathrm{MPa}$ for the $30 \mathrm{wt}$ \% filled PBS (100\% increase). Fig. 9 shows the tensile fracture strain. The PLA is a very brittle material and the inclusion of the filler will make this material worse.

Moreover, whatever the milled olive pit size is, a decrease in strength as the filler content increases is observed indicating the presence of a poor interfacial adhesion between the hydrophilic lignocellulosic powder and the hydrophobic PLA which does not allow efficient stress transfer between the two phases of the biocomposite. This lack of adhesion is confirmed through ESEM observations (Fig. 10) especially in the case of olive pits B and C. Indeed, in several locations of the inner

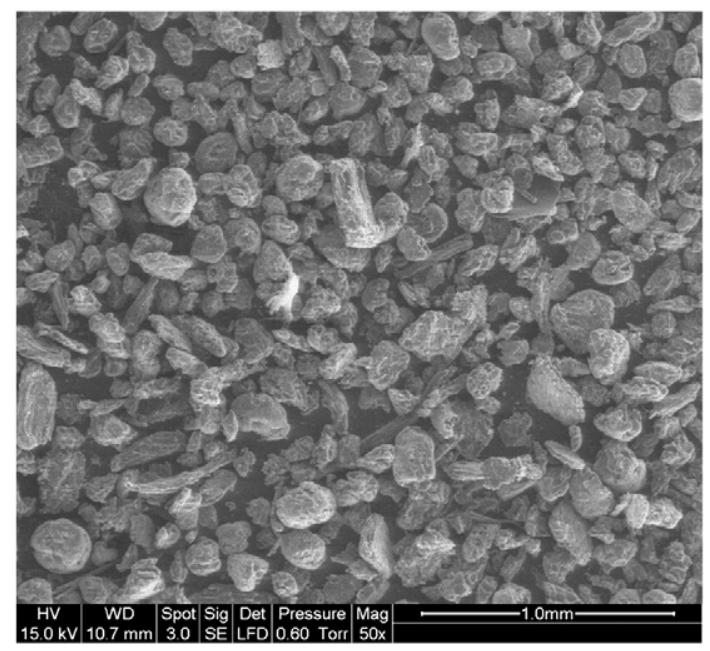

Fig. 6. Olive pit powder B, mag. $50 \times$.

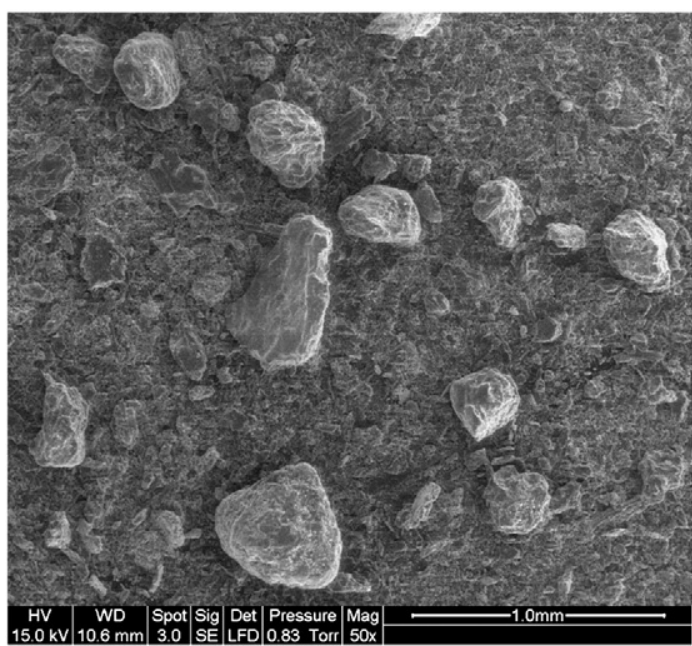

Fig. 7. Olive pit powder C, mag. $50 \times$.

structure and especially in the interfacial area extended between particle fillers and the matrix some gaps or entrapped air to a great extent can be observed which indicates bad inclusion-matrix adhesion.

For olive pit powder A, agglomerates are observed that may also induce a decrease in strength. Such a decrease was also described in the literature [20] for PBS/30 wt.\% olive husk flour biocomposite (46\% decrease). Papanicolaou et al. [9] reported a $48 \%$ increase in bending modulus and a $45 \%$ reduction in tensile strength in the case of epoxy/olive pit powder (45 wt.\%) composites.

\section{Conclusions}

In the present work a novel composite material containing olive pit powders dispersed in PLA matrix was manufactured and studied. The aim of this study was to investigate the effect of three types of olive pit powders at different weight fractions on the physical and mechanical properties of polylactide (PLA) matrix composites.

For the preparation of the powder, two different grinding procedures were applied; producing three types of olive pit powders. Various measurements were accomplished to determine characteristics such as the density, the size distribution and the shape of the powder. Different PLA/pit composites with filler diameter, $d=30,60$, and $170 \mu \mathrm{m}$ at wt. $\%=5$, and 10 and wt.\% = 5, 10, 15 and 20 were manufactured. A comparative study of the different composites was made to investigate the matrix-filler interactions, occurring between the PLA and olive pit powders. The main conclusions can be summarized as follows:

1. The grinding method applied affects the size distribution as well as the physical and morphological characteristics of the olive pit granules at different granulometric factors. Powders A and B grinded by the high speed rotor centrifugal mill have similar fine distributions and spherical shape in contrast with the ball milled olive pit C, which shows wide size distribution and flakes alike granules.

Table 4

Evolution of thermal characteristics (glass transition Tg, crystallization temperature Tc, melting temperature Tm, crystallinity ratio Xc) of PLA/olive pit powder biocomposites.

\begin{tabular}{llllll}
\hline wt.\% olive pits & & $\operatorname{Tg}\left({ }^{\circ} \mathrm{C}\right)$ & $\operatorname{Tc}\left({ }^{\circ} \mathrm{C}\right)$ & $\operatorname{Tm}\left({ }^{\circ} \mathrm{C}\right)$ & Xc (\%) \\
\hline $0 \%$ & & 65.8 & 125.1 & 155.1 & 8.5 \\
$5 \%$ & A & 66.9 & 125.4 & 154.2 & 8.2 \\
& B & 65.8 & 127.3 & 155.2 & 6.9 \\
\multirow{2}{*}{$10 \%$} & C & 63.1 & 121.1 & 153.6 & 15.9 \\
& A & 66.8 & 124.4 & 155.6 & 12.5 \\
& B & 62.6 & 123.3 & 153.2 & 12.5 \\
& C & 62.2 & 121.0 & 153.9 & 14.0 \\
\hline
\end{tabular}


Table 5

Degradation temperature and mass loss of PLA/olive pit powder biocomposites.

\begin{tabular}{llll}
\hline wt.\% olive pits & & Degradation temperature $\left({ }^{\circ} \mathrm{C}\right)$ & Mass loss (wt.\%) \\
\hline $0 \%$ & & 306 & 98.6 \\
$5 \%$ & A & 286 & 94.7 \\
& B & 283 & 96.7 \\
& C & 290 & 97.3 \\
& A & 260 & 91.9 \\
& B & 255 & 93.5 \\
$15 \%$ & C & 270 & 94.8 \\
& B & 248 & 92.1 \\
$20 \%$ & C & 249 & 92.4 \\
\hline
\end{tabular}

2. Thermal analysis of the olive powders $A$ and $C$ shows that no significant changes on the thermal degradation temperature occurred which might means that the different mechanical processing of olive pits applied for the preparation in a powder form does not affect the thermal behavior. This is consistent with the processing temperatures of biocomposites.

3. With filler loading, an increase in the tensile modulus on the order of $18 \%$ and $16 \%$ for PLA/olive pit powders A and B was achieved at wt. $\%=20$ and $13 \%$ for PLA/olive pit powder C at wt. $\%=5$.

4. A small decrease in tensile strength with filler volume fraction was observed.

Milled olive pits can be used as reinforcements in PLA so that a full bio-based composite is produced. The flexural strength reduction may

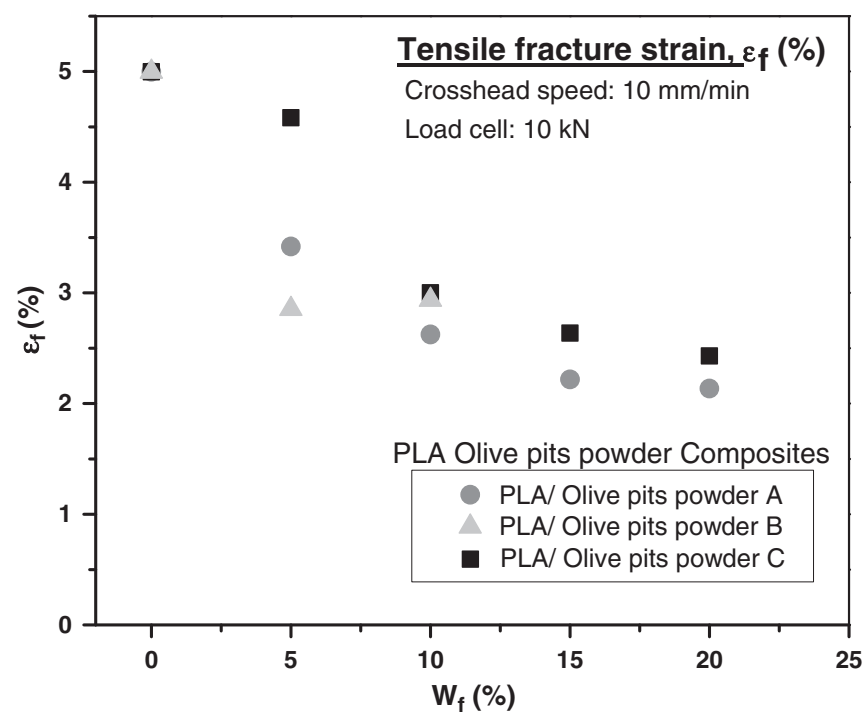

Fig. 9. Tensile fracture strain of neat PLA and PLA/olive powder composites vs. the \% fillerweight fraction.

be due to the poor interfacial bonding between olive pit powder and PLA. From a general point of view this is the main disadvantage encountered during the incorporation of natural lignocellulosic materials into polymers. Therefore suggestions to achieve a better interfacial bonding are reported in literature [20-22].
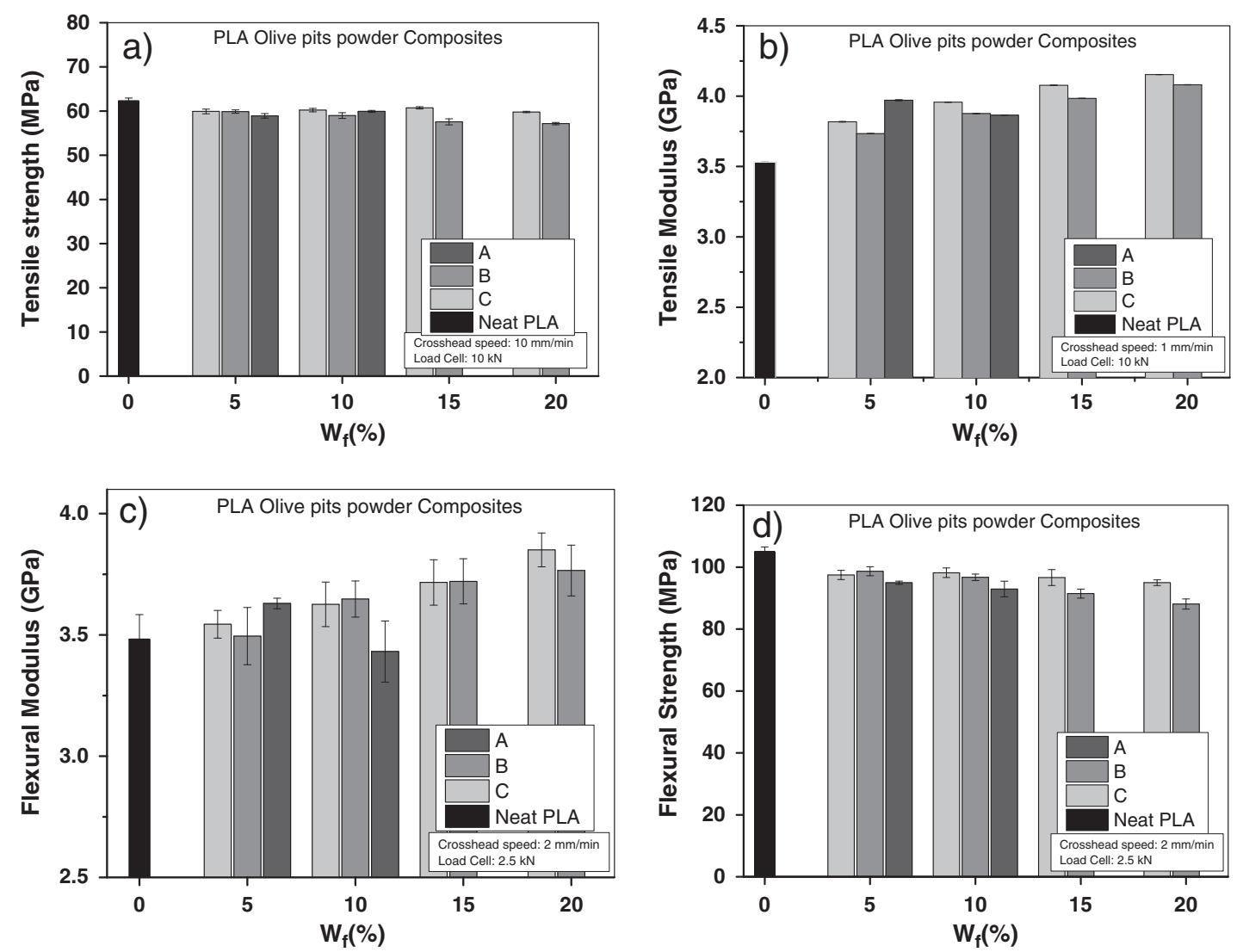

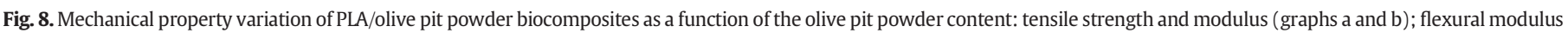
and strength (graphs $\mathrm{c}$ and d) for neat PLA (black color), powder A (dark gray color), powder B (gray color) and powder C (light gray). 
a

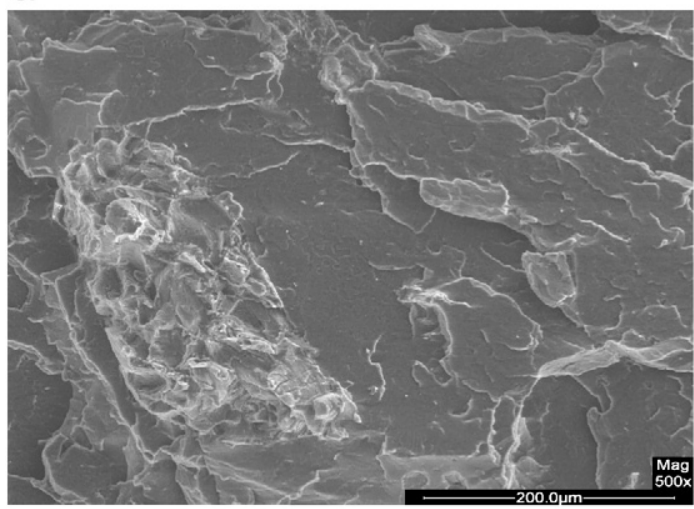

b

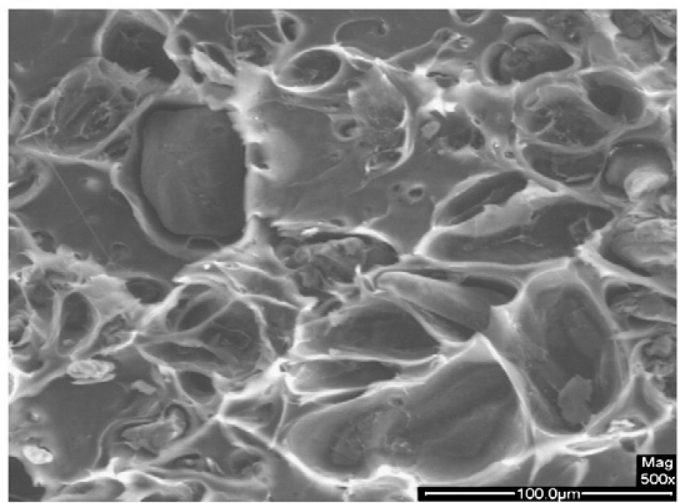

C

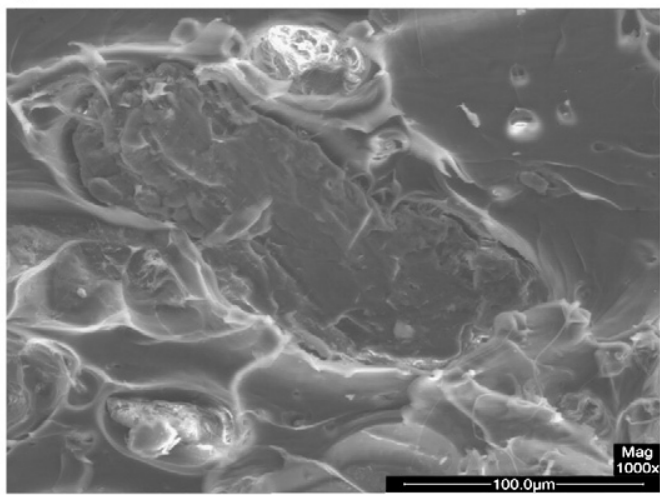

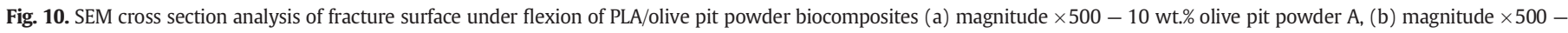
15 wt.\% olive pit powder B and (c) magnitude $\times 1000-15$ wt.\% olive pit powder C.

\section{Acknowledgment}

The authors are grateful to Mr Konstantinos Papaefthymiou for his great help in manufacturing the olive pit powder C.

\section{References}

[1] S. Kalia, Singhania, B.S. Kaith, I. Kaur, Cellulose fibers: bio- and nano-polymer composites, Green Chemistry and Technology, Springer, 2011.

[2] HGCA, Industrial uses for crops, http://www.hgca.com/document.aspx?fn= load\&media_id $=5267$ \&publi1 cationId $=5989$.

[3] T. Mukherjee, N. Kao, PLA based biopolymer reinforced with natural fibre: a review, J. Polym. Environ. 19 (3) (2011) 714-725.

[4] L.T. Lim, R. Auras, M. Rubino, Processing technologies for poly(lactic acid), Prog. Polym. Sci. 33 (8) (2008) 820-852.

[5] T. Miranda, A. Esteban, S. Rojas, I. Montero, A. Ruiz, Combustion analysis of different olive residues, Int. J. Mol. Sci. 9 (4) (2008) 512-525.

[6] G. Rodríguez, A. Lama, R. Rodríguez, A. Jiménez, R. Guillén, J. Fernández-Bolaños, Olive stone an attractive source of bioactive and valuable compounds, Bioresour. Technol. 99 (13) (2008) 5261-5269.

[7] V. Tserki, P. Matzinos, S. Kokkou, C. Panayiotou, Novel biodegradable composites based on treated lignocellulosic waste flour as filler. Part I. Surface chemical modification and characterization of waste flour, Compos. A: Appl. Sci. Manuf. 36 (7) (2005) 965-974.

[8] A. Bergeret, J.C. Benezet, Natural fibre-reinforced biofoams, Int. J. Polym. Sci. 2011 (2011) 14 pages, http://dx.doi.org/10.1155/2011/569871(article ID 569871).

[9] G.C. Papanicolaou, A.F. Koutsomitopoulou, A. Sfakianakis, Effect of thermal fatigue on the mechanical properties of epoxy matrix composites reinforced with olive pits powder, J. Appl. Polym. Sci. 124 (1) (2012) 67-76.

[10] I.M. De Rosa, C. Santulli, F. Sarasini, Mechanical and thermal characterization of epoxy composites reinforced with random and quasi-unidirectional untreated Phormium tenax leaf fibers, Mater. Des. 31 (5) (2010) 2397-2405.
[11] L. Suryanegara, A. Nakagaito, H. Yano, Thermo-mechanical properties of microfibrillated cellulose-reinforced partially crystallized PLA composites, Cellulose 17 (4) (2010) 771-778

[12] A. Pei, Q. Zhou, L.A. Berglund, Functionalized cellulose nanocrystals as biobased nucleation agents in poly(l-lactide) (PLLA) - crystallization and mechanical property effects, Compos. Sci. Technol. 70 (5) (2010) 815-821.

[13] J.F. Gonzalez, C.M. Gonzia, A. Ramiro, J. Gonzalez, E. Sabio, J. Ganan, Combustion optimization of biomass residue pellets for domestic heating with a mural boiler, Biomass Energy 27 (2004) 145-154.

[14] G. Siracusa, A.D.L. Rosa, V. Siracusa, M. Trovato, Eco-compatible use of olive husk as filler, Thermoplastic Composites, 9 (4), 2002.

[15] A. Garcia-Maraver, M. Zamorano, A. Ramos-Ridao, L.F. Diaz, Thermogravimetric analysis in an oxidative environment and chemical composition of olive trees waste, 8-11 November 2010.

[16] A. Awal, M. Sain, Spectroscopic studies and evaluation of thermorheological properties of softwood and hardwood lignin, J. Appl. Polym. Sci. 122 (2) (2011) 956-963.

[17] D. Garlotta, A literature review of poly (lactic acid), J. Polym. Environ. 9 (2) (2001) 63-84.

[18] S. Perinovic, B. Andricic, M. Erceg, Thermal properties of poly(L-lactide)/olive stone flour composites, Thermochim. Acta 510 (2010) 97-102.

[19] M.S. Huda, L.T. Drzal, M. Misra, A.K. Mohanty, Wood-fiber-reinforced poly (lactic acid) composites: evaluation of the physico-mechanical and morphological properties, J. Appl. Polym. Sci. 102 (5) (2006) 4856-4869.

[20] V. Tserki, P. Matzinos, C. Panayiotou, Novel biodegradable composites based on treated lignocellulosic waste flour as filler. Part II. Development of biodegradable composites using treated and compatibilized waste flour, Compos. Part A 37 (9) (2006) 1231-1238.

[21] G. Frisoni, M. Baiardo, M. Scandola, D. Lednicka, M.C. Cnockaert, J. Mergaert, Natura cellulose fibers: heterogeneous acetylation kinetics and biodegradation behavior Biomacromolecules 2 (2001) 476-482.

[22] R. Mahlberg, H.E.M. Niemi, F. Denes, R.M. Rowell, Effect of oxygen and hexamethyldisiloxane plasma on morphology, wettability and adhesion properties of polypropylene and lignocellulosics, Int. J. Adhes. Adhes. 18 (1998) 283-297. 